\title{
Self-expandable metallic stent for treatment of malignant colorectal strictures in elderly patients: our experience F Cantarella1 ${ }^{1}$ P Ricci1 ${ }^{1}$ E Cavazzoni ${ }^{1}$, L Graziosi ${ }^{1}$, N Abu Qweider ${ }^{1}$, W Bugiantella*1, S Mosca ${ }^{2}$ and A Donini ${ }^{1}$
}

Address: ${ }^{1}$ Department of Surgery, Section of General and Emergency Surgery S. Maria della Misericordia Hospital, University of Perugia, Perugia, Italy and 2 Section of Radiology, S. Maria della Misericordia Hospital, University of Perugia, Perugia, Italy

* Corresponding author

from XXI Annual Meeting of The Italian Society of Geriatric Surgery

Terni, Italy. 4-6 December 2008

Published: I April 2009

BMC Geriatrics 2009, 9(SuppI I):A36 doi:10.1 I86/I47I-23I8-9-SI-A36

This abstract is available from: http://www.biomedcentral.com/I47I-23I8/9/SI/A36

(c) 2009 Cantarella et al; licensee BioMed Central Ltd.

\section{Background}

Intrinsic obstruction caused by primary or recurrent adenocarcinoma and extrinsic invasion/compression due to pelvic malignancies represent the main causes for malignant colorectal obstruction. Most of the patients with acute or chronic large bowel obstruction are often in poor general condition (severe dehydration, electrolytes imbalance, advanced age, co-pathology) facing high risks as surgical candidates. Self-Expandable metallic stents (SEMS) allow rapid decompression of colonic obstruction reducing operative procedures of $23 \%$ and number of colostomies from $43 \%$ to $7 \%$, which result in a worsening of the quality of life and higher costs. The end-point of our preliminary experience is to evaluate if colonic stenting is feasible for both palliation or "bridge" to surgery in elderly patients.

\section{Materials and methods}

From December 2007 to November 2008 at our Unit, three patients underwent colonic stenting: an 88 year old male, suffered for cardiac ischemia and obstructive respiratory syndrome, affected by stenotic and metastatic sigmoid neoplasia (stage IV); a 72 year old female affected by endometrial adenocarcinoma relapse infiltrating the left urether and the sigma; a 68 year old female affected by locally advanced and metastatic adenocarcinoma of the recto-sigmoid junction (stage IV) (Figures 1, 2).
All patients received WallFlex ${ }^{\mathrm{TM}}$ colonic stent. Prophylactic antibiotics were administered. Stent insertion was performed under fluoroscopic guidance (Figures 3, 4, 5, 6). Patients had a plain abdominal radiograph 48 hours later to confirm stent full expansion.

\section{Results}

In all patients successful decompression, defined as complete relief of bowel obstruction as judged by clinical symptoms and radiographic observation, was achieved.

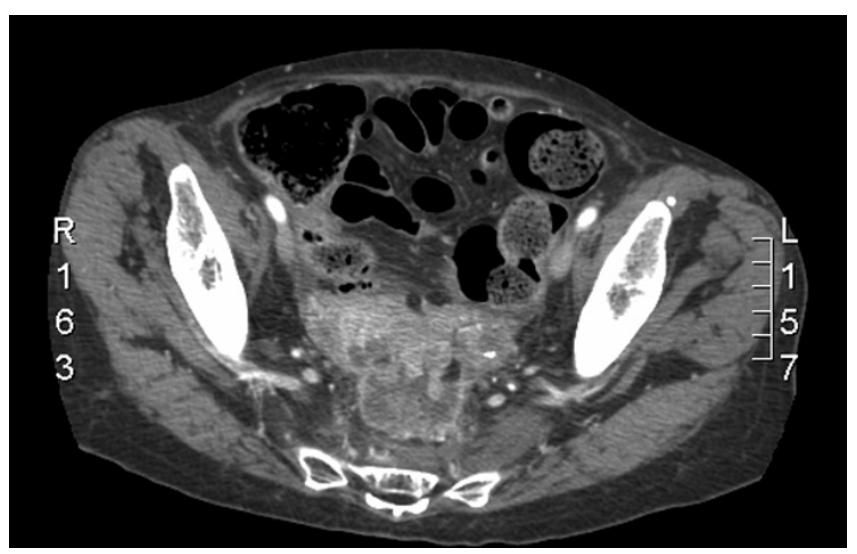

Figure I

Locally advanced adenocarcinoma of the recto-sigmoid junction. 


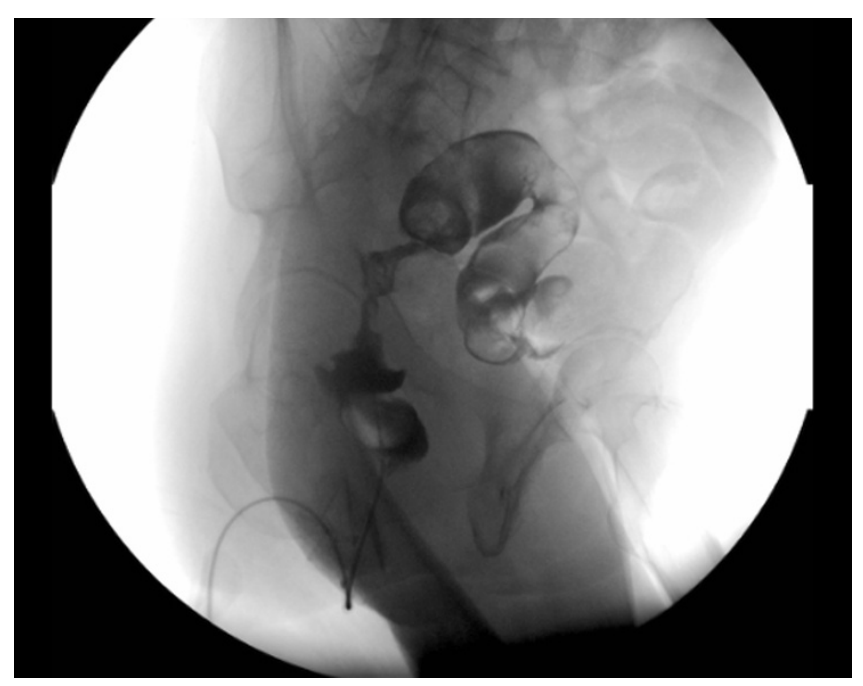

Figure 2

Tight stenosis of the rectum at gastrografin enema.

No precocious or posthumous complications were observed. The first patient died 1 month later for disease progression. The second patient underwent the VIII cycle with Adriamicina and Cisplatino. At 9 months from stent insertion a CT exam showed disease progression, no sign of stent dislocation (Figures 5, 6). The last patient has completed the I cycle with FOLFOX.

\section{Conclusion}

Our experience suggests that colonic stenting in elderly patients is safe and minimally invasive, allowing a colonic decompression in both intrinsic and extrinsic neoplasia, with a better quality of life, less morbidity, mortality and

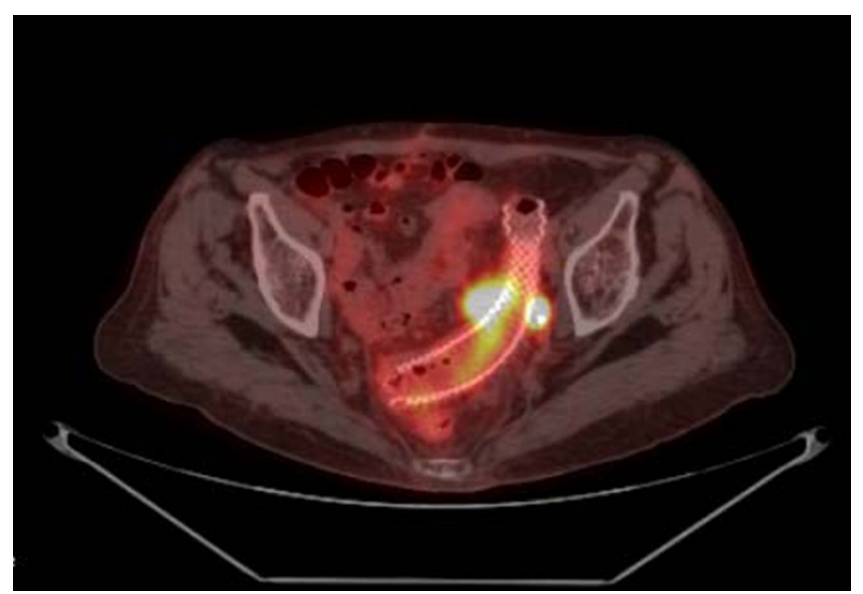

Figure 3

PET-CT aspect at 5 months from stenting procedure in 72 yo female affected of endometrial adenocarcinoma relapse. Cross section.

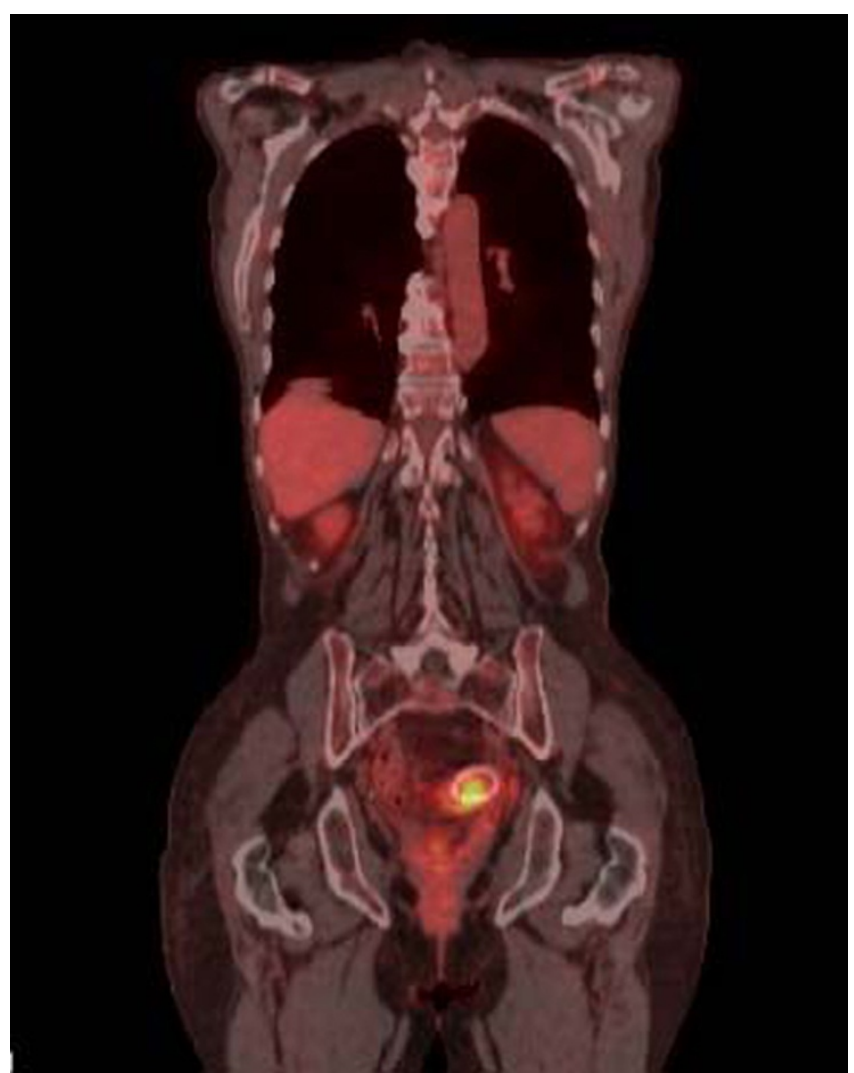

Figure 4

Frontal section.

costs. It doesn't affect the median survival compared with surgery.

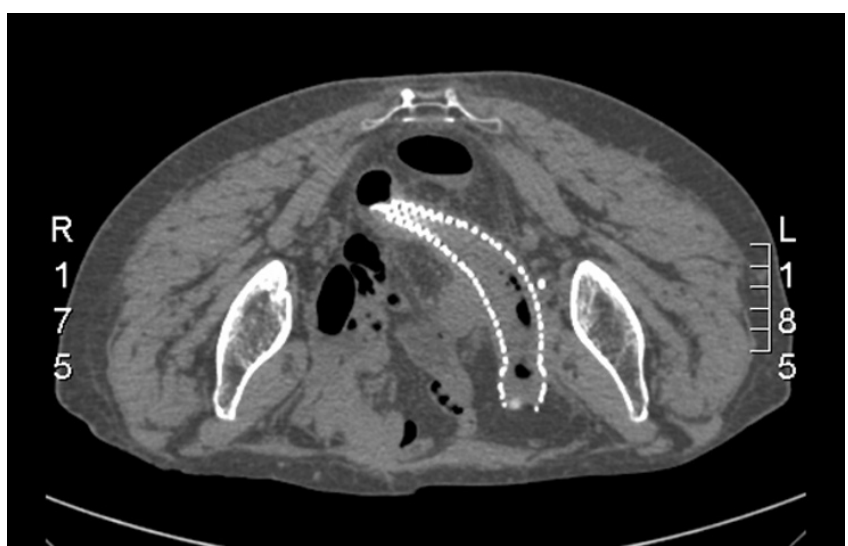

Figure 5

CT at 9 months no evidence of stent dislocation. 


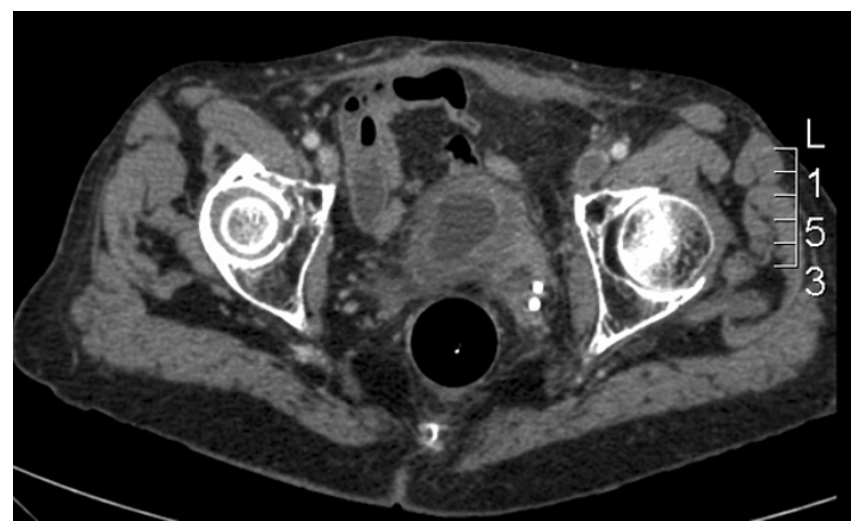

\section{Figure 6}

CT aspect of disease progression.

Publish with Biomed Central and every scientist can read your work free of charge

"BioMed Central will be the most significant development for disseminating the results of biomedical research in our lifetime. " Sir Paul Nurse, Cancer Research UK

Your research papers will be:

- available free of charge to the entire biomedical community

- peer reviewed and published immediately upon acceptance

- cited in PubMed and archived on PubMed Central

- yours - you keep the copyright 